\title{
STUDI KOMPARATIF KINERJA PORTOFOLIO SAHAM SMALL MEDIUM ENTERPRISE (SME) DI PASAR MODAL INDONESIA, CHINA, DAN INDIA
}

\author{
Ni Luh Putu Sri Sandhi ${ }^{1}$ \\ Ida Bagus Panji Sedana ${ }^{2}$ \\ Luh Gede Sri Artini ${ }^{3}$
}

\author{
${ }^{1,2,3}$ Fakultas Ekonomi dan Bisnis Universitas Udayana, Bali, Indonesia \\ ${ }^{1}$ Email: ssandhi@gmail.com
}

\begin{abstract}
ABSTRAK
Studi ini bertujuan untuk mengetahui dan membandingkan kinerja dari portofolio saham SME di Pasar Modal Indonesia, China dan India berdasarkan Indeks Sharpe serta signifikansi perbedaan rata-rata kinerja di ketiga pasar modal tersebut. Studi komparasi ini menggunakan data historis harga saham SME di Pasar Modal Indonesia (BEI), China (SZSE) dan India (BSE) serta data suku bunga bank sentral Indonesia (BI Rate), China (PBC base interest rate) dan India (RBI repo rate) periode Januari 2014 s.d. Januari 2015. Metode purposive sampling digunakan untuk menentukan jumlah sampel sebanyak 15 saham SME. Hasil studi menunjukkan, berdasarkan Indeks Sharpe kinerja portofolio dari saham SME di Pasar Modal Indonesia dan Pasar Modal China lebih baik daripada kinerja saham komposit dan kinerja saham A-list sedangkan di Pasar Modal India kinerja portofolio saham SME lebih baik dibandingkan kinerja saham A-list namun masih di bawah kinerja saham komposit. Berdasarkan uji komparatif dengan metode ANOVA satu jalur, perbedaan rata-rata kinerja portofolio dari saham SME di Pasar Modal Indonesia, China dan India tidak signifikan.
\end{abstract}

Kata Kunci : SME, pasar modal, saham, kinerja portofolio, Indeks Sharpe

\begin{abstract}
The purpose of this study is to compare the share portfolio performance of SMEs in the Indonesian, Chinese and Indian capital markets based on the Sharpe Index and to learn the significance difference of the average of portfolio performance between the three capital markets. This study used historical data of stock prices of SMEs and the interest rate of the central bank of Indonesia (BI Rate), China (PBC base interest rate) and India (RBI repo rate) in the period of January 2014 through January 2015. Purposive sampling method is the sampling technique used to obtain a total sample of 15 stocks of SMEs. The findings show that the share portfolio performance of SMEs based on the Sharpe index in Capital Market of Indonesia and China is better than the performance of composite index and the performance of A-list share index in respective capital market, while in Indian Capital Markets the share portfolio performance of SMEs is better than the performance of the Alist share index but still below the performance of the composites index. Statistically based on one-way ANOVA, the difference of the average of SMEs portfolio performance between the Indonesian, Chinese, and Indian capital market, is not significant.
\end{abstract}

Keywords: SMEs, capital markets, shares, portfolio performance, Sharpe Index 


\section{PENDAHULUAN}

Investasi pada Small and Medium Enterprises (SME) atau emiten kecil dan menengah merupakan alternatif investasi bagi investor yang diharapkan memberikan return yang lebih kompetitif daripada hanya berinvestasi pada emiten besar. Banz (1981) dan Ziemba (1991) di Jepang, Levis (1985) di Inggris dan Brown, et al. (1983) di Australia menemukan bahwa kinerja saham dari perusahaan dengan kapitalisasi kecil secara konsisten melampaui kinerja saham dari perusahaan dengan kapitalisasi besar (Tudor, et al., 2014).

Berdasarkan data Bank Dunia (2016) besar konsumsi domestik China, Indonesia dan India terhadap GDP nya adalah masing-masing sebesar 37,45\%, 56,79\% dan 57,95\%. Menurut IMF World Economic Outlook (2016), China, India dan Indonesia merupakan tiga negara dengan rata-rata pertumbuhan ekonomi terbesar dalam periode lima tahun terakhir setelah tekanan kondisi global yang semakin kuat di tahun 2009.

SME dan usaha mikro menyumbangkan rata-rata $42 \%$ dari nominal gross domestic product (GDP) di negara-negara ASM (ADB, 2015). Menurut Tambunan (2009), SME memiliki peran yang sangat penting bagi ekspor di negara-negara Asia. Berdasarkan Asia SME Finance Monitor (2014), SME menyumbangkan $40 \%$ dari total nilai ekspor negara China dengan pertumbuhan sebesar 7\% pada tahun 2012 dan 10\% pada tahun 2013. Sumbangan nilai ekspor SME pada beberapa negara lain seperti Thailand, sebesar $26 \%$ dari total nilai ekspor di tahun 2013, Korea sebesar 19\% pada tahun 2012 dan di Indonesia sebesar 16\% di tahun 2013. Pertumbuhan nilai ekspor SME di India dan Indonesia 
adalah sebesar 9\% pada tahun 2013. Perdagangan dan investasi bebas yang merupakan dampak dari integrasi ekonomi membuka peluang yang makin luas bagi SME untuk berperan lebih banyak (ADB, 2015).

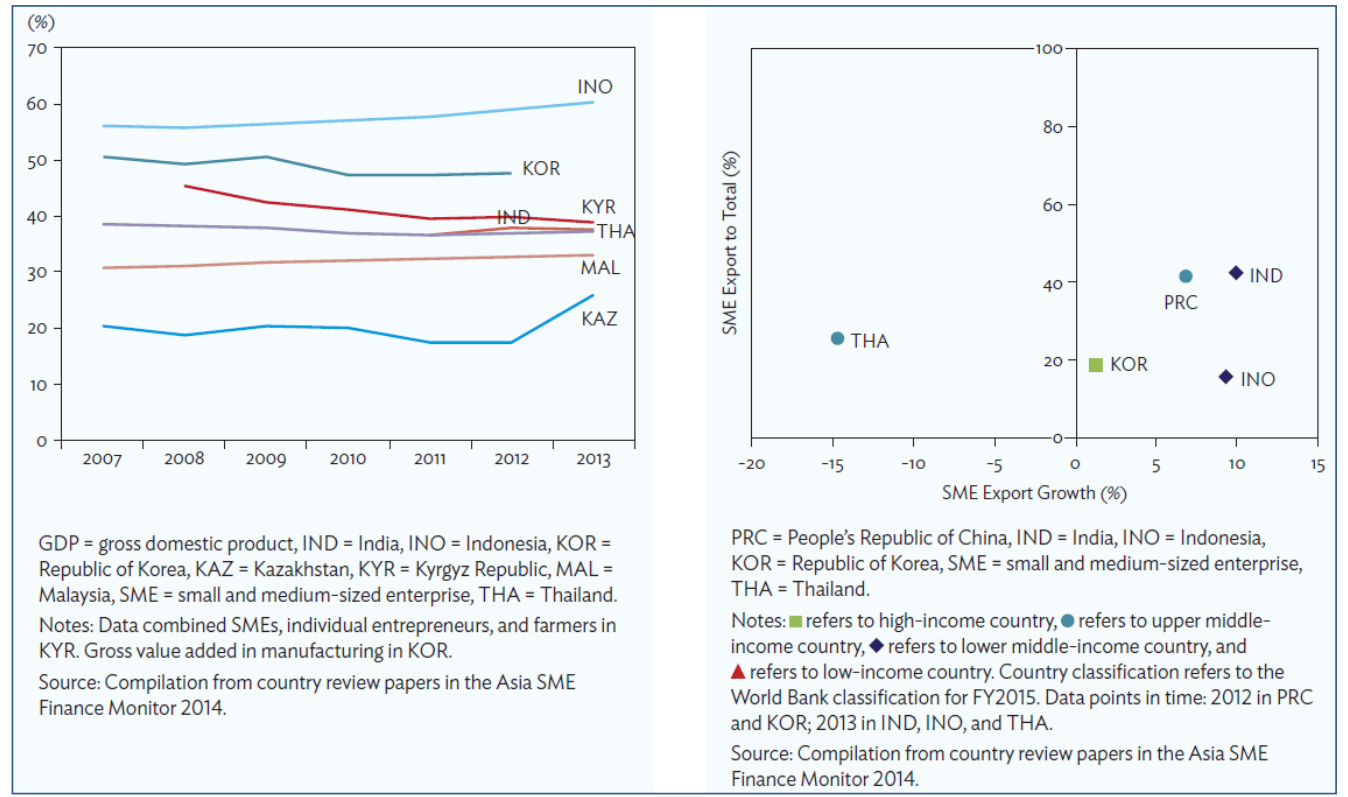

Gambar 1. Kontribusi SME pada GDP dan Ekspor

Sumber : Asia SME Finance Monitor (2014)

Peranan yang cukup signifikan dari SME bagi perekonomian negara mendorong Pemerintah Indonesia, China dan India mengembangkan berbagai program pengembangan SME. Tantangan pengembangan SME di negara berkembang hampir sama. SME di Indonesia lebih membutuhkan fasilitasi dalam hal perdagangan (Tambunan, 2009), SME di India lebih memperhatikan pengembangan pemasok, pemeliharaan tingkat produktivitas total serta budaya organisasi sedangkan SME di Cina lebih memperhatikan manajemen hubungan serta pengurangan biaya (Singh, et al, 2009). Menurut Shinozaki (2014), SME merupakan tulang punggung bagi kelenturan ekonomi nasional karena sifat dari SME yang menstimulasi permintaan domestik melalui penciptaan lapangan kerja, inovasi dan kompetisi. SME menciptakan diversifikasi pasar, menumbuhkan 
inovasi dan menyediakan kesempatan kerja yang luas, namun dalam prakteknya sebagian besar SME umumnya kesulitan dalam mendapatkan pendanaan (Barth, 2011). Pertumbuhan pesat dari negara-negara berkembang di Asia mengakibatkan meningkatnya kebutuhan pendanaan jangka panjang dan pasar modal yang kuat sebagai saluran alternatif penyediaan dana untuk pertumbuhan ekonomi. Pemimpin negara G20 menyatakan penting untuk menciptakan pendanaan jangka panjang bagi SME dalam konteks investasi (Shinozaki, 2014).

SME berperan penting terhadap pertumbuhan dan perkembangan ekonomi di India, dan dalam beberapa tahun terakhir menunjukkan pertumbuhan yang lebih tinggi dibandingkan dengan keseluruhan sektor industri. Ketangguhan, dinamisme, inovasi serta kemampuan beradaptasi SME menyebabkan dapat bertahan dari perlambatan ekonomi dan resesi yang terjadi. Pasar modal untuk SME telah dikembangkan di India yaitu sejak Maret 2012 yang ditandai dengan peluncuran flatform khusus untuk SME yang disebut dengan SME Exchange oleh Bombay Stock Exchange (BSE). Sampai dengan 19 Nopember 2013, tercatat sebanyak 41 SME sebagai emiten (Shinozaki, 2014). BSE SME IPO index diluncurkan pada 14 Desember 2012 sebagai acuan bagi investor untuk memantau kinerja perusahaan SME yang terdaftar di BSE. Saat ini kurang lebih terdapat 104 perusahaan yang telah dilisting pada flatform SME di BSE.

China pada tahun 2014 memiliki SME sebanyak kurang lebih 15,4 juta perusahaan dan membentuk sektor-sektor paling dinamis pada ekonomi China. SME tersebut berkontribusi sebesar $60 \%$ terhadap GDP nasional, 70\% ekspor, serta $70 \%$ paten karena penemuan teknologi dan $80 \%$ lapangan pekerjaan di 
perkotaan. Hal tersebut menunjukkan semakin pentingnya SME bagi pertumbuhan ekonomi di China (SZSE, 2014). Dukungan terhadap SME di China ditandai dengan ditetapkannya kebijakan SME Promotion dan pembentukan SME Board pada tahun 2004 dibawah SZSE. Diluncurkannya ChiNext Market pada tahun 2009 merupakan respon terhadap krisis finansial global. SME Board dan ChiNext Market sampai dengan saat ini telah mengumpulkan 157 milyar USD bagi 1.098 SME atau perusahaan inovatif pemula (SZSE, 2014). Index SMEChiNext 100 yang diluncurkan pada bulan Februari 2011 menunjukkan perolehan return (ROE) yang tinggi dan secara umum dinyatakan sebagai benchmark untuk saham small cap (Van Eck, 2015).

Bursa Efek Indonesia (BEI) belum memiliki flatform khusus bagi SME, sebagai acuan bagi investor, BEI dan lembaga rating PT. Pemeringkat Efek Indonesia (PEFINDO) meluncurkan Indeks PEFINDO25 pada tanggal 18 Mei 2009 yang merupakan indeks harga saham emiten kecil dan menengah (SME). Sebanyak 25 emiten kecil dan menengah membentuk tersebut dan tercatat di BEI. Sejak diperkenalkan, indeks tersebut mempunyai potensi yang baik dan pelaksanaan proses seleksi saham-saham dilakukan dengan konsisten dan melalui beberapa kriteria yang ketat khususnya pada kinerja keuangan dan kinerja likuiditas saham di pasar.

ChiNext Market - SZSE, berkembang cukup pesat pada tahun 2013 yang ditunjukkan dengan meningkatnya ChiNext Composite Index menjadi 74,7\% (SZSE, 2013). S\&P BSE SME Index yang diluncurkan pada bulan Agustus 2012, menghasilkan return sebesar 129\% selama tahun 2012 (India Times, 2013). Sejak 
akhir tahun 2009 sampai akhir tahun 2012, indeks PEFINDO25 mencapai ratarata pertumbuhan 31,3\% CAGR. Rata-rata pertumbuhan Indeks PEFINDO25 tercatat lebih baik dibandingkan indeks lainnya yang tidak lebih dari $20 \%$. (Pefindo, 2013).

Investor risk averse akan lebih memilih "emerging blue chips" dalam portofolionya karena keyakinan terhadap pertumbuhan yang tinggi dari perusahaan muda dan inovatif daripada memilih saham-saham dari emiten yang sudah mapan. Tren investor yang memilih alternatif investasi pada saham-saham berkapitalisasi pasar kecil dan menengah di bursa negara-negara berkembang (emerging market) menyebabkan indeks harga saham untuk Small Medium Enterprises (SME) cenderung meningkat.

Penelitian portofolio saham dan kinerja portofolio saham sebelumnya sebagian besar menggunakan saham-saham yang likuid, blue chip ataupun sahamsaham yang berkapitalisasi besar untuk membentuk portofolio saham. Penelitian terhadap kinerja portofolio saham SME dilakukan oleh Tudor, et al (2014) yang meneliti kinerja portofolio saham SME di pasar modal Romania (Bucharest Stock Exchange). Hasil penelitian menunjukkan berinvestasi pada saham-saham SME akan mendapatkan kinerja pasar terbaik berdasarkan hasil perhitungan dengan metode risk-adjusted performance. Pentingnya peranan SME dan dukungan pemerintah terhadap perkembangan SME di Indonesia serta pada negara-negara berkembang, perkembangan pasar modal untuk SME di negara Indonesia, India dan China, dan jumlah penelitian terkait kinerja portofolio saham SME yang masih sangat sedikit mendorong penelitian pengukuran kinerja portofolio saham 
SME di pasar modal Indonesia dengan perbandingan pada pasar modal negara India dan China ini dilakukan.

Kinerja portofolio saham SME pada penelitian dihitung dengan riskadjusted return karena: (1) secara teoritis, ukuran kinerja portofolio yang menggabungkan return dan risiko memungkinkan untuk melakukan perbandingan portofolio secara langsung dengan tingkat return dan risiko yang berbeda-beda, (2) dapat mencerminkan hubungan antara return dan risiko apabila investor menyusun portofolio berdasarkan teori portofolio (Sharpe, 1964). Indeks Sharpe membagi premi risiko portofolio dengan standar deviasi. Standar deviasi mewakili risiko total yaitu penjumlahan unsystematic risk dan risiko pasar (systematic/market risk) (Tandelilin, 2010). Risiko pasar pada masing-masing pasar modal di Indonesia, China dan India akan tercermin/diperhitungkan pada risiko total (standar deviasi) dalam pengukuran kinerja dengan Indeks Sharpe. Pemilihan Indeks Sharpe sebagai pengukuran kinerja portofolio saham juga disebabkan karena penelitian ini tidak memperhatikan tingkat diversifikasi dari portofolio yang dibentuk.

Pokok permasalahan dalam studi ini berdasarkan uraian latar belakang adalah : 1) Bagaimanakah kinerja portofolio saham SME di Pasar Modal Indonesia, China dan India dibandingkan dengan kinerja Indeks Komposit dan Indeks saham A-List di masing-masing pasar modal pada periode Januari 2014 Januari 2015? 2) Apakah terdapat perbedaan rata-rata kinerja portofolio saham SME yang dibentuk di pasar modal Indonesia, India, dan China pada periode Januari 2014 - Januari 2015? 
Studi ini bertujuan untuk : 1) mengetahui kinerja dari portofolio saham SME di Pasar Modal Indonesia, China dan India dibandingkan dengan kinerja Indeks Komposit dan Indeks saham A-List di masing-masing pasar modal pada periode Januari 2014 - Januari 2015, 2) mengetahui signifikansi perbedaan ratarata kinerja dari portofolio saham SME di pasar modal Indonesia, India dan China periode Januari 2014 - Januari 2015.

SME merupakan pembentuk tulang punggung suatu ekonomi pasar yang kuat, namun pada pasar negara berkembang, pilihan sumber pendanaan sangatlah terbatas sehingga terdapat kekosongan pada struktur ekonomi menengah. Investor mempercayai bahwa dengan dilakukan penelitian dan pengawasan yang ketat, investasi pada SME memberikan peluang untuk memfasilitasi perkembangan SME di pasar negara berkembang dan pada saat yang sama mendapatkan return finansial yang berkelanjutan (Wood, et.al., 2010). Menurut ADB (2014), di Asia terdapat tujuh negara yang menyediakan peluang pendanaan melalui pasar modal bagi SME yang berpotensi tinggi. Ketujuh negara tersebut diantaranya adalah China, India, Korea, Filipina, Malaysia, Thailand dan Vietnam.

Perbedaan perkembangan akses pendanaan melalui pasar modal dan fasilitasi yang diberikan pada Negara China, India dan Indonesia diduga memiliki pengaruh terhadap perbedaan kinerja dari saham SME yang diperdagangkan. Berdasarkan hal-hal tersebut studi komparatif terhadap kinerja dari portofolio saham SME di pasar modal Indonesia, India dan China dilakukan dan diduga kinerja portofolio saham SME di ketiga negara tersebut berbeda secara signifikan. Berdasarkan hal tersebut hipotesis dalam studi ini adalah sebagai berikut : 
$\mathrm{H}_{0}=$ Rata-rata kinerja dari portofolio saham SME di pasar modal Indonesia sama dengan di pasar modal China dan di pasar modal India.

$\mathrm{H}_{1}=$ Terdapat perbedaan antara rata-rata kinerja dari portofolio saham SME di pasar modal Indonesia dengan di pasar modal China dan di pasar modal India.

\section{METODE PENELITIAN}

Studi ini adalah comparative research yang membandingkan kinerja dari portofolio saham SME di pasar modal Indonesia, China dan India. Data yang digunakan adalah data kuantitatif dan kualitatif. Data kuantitatif adalah harga saham penutupan selama periode penelitian yakni periode Januari 2014 s.d. Januari 2015 diperoleh dari website www.finance.yahoo.com, data BI Rate pada website $w w w . b i . g o . i d$, data suku bunga bank sentral India dan China pada website www.global-rates.com. Data kualitatif merupakan keterangan-keterangan yang berkaitan dengan Indeks Pefindo25, Indeks S\&P BSE SME IPO, dan Indeks SME-CHINEXT 100 serta sejarah singkat dan perkembangan pasar modal khususnya platform SME baik pasar modal Indonesia, India, dan China.

Variabel yang diteliti dalam penelitian ini baik di pasar modal Indonesia, India, dan China adalah :

1) Return saham SME individual adalah return dari masing-masing saham SME individual yang masuk dalam Indeks Pefindo25 (Indonesia), Indeks S\&P BSE SME IPO (India), dan Indeks SME-CHINEXT 100 (China) pada periode pengukuran yaitu tahun 2014 dan periode kepemilikan yaitu 1, 3, dan 6 bulan. 
Pengukuran return saham individual menggunakan persamaan sebagai berikut (Jones, 2014) :

$$
\begin{aligned}
& T R=\frac{C F_{t}+\left(P_{E}-P_{B}\right)}{P_{B}} \\
& T R=\frac{C F_{t}+P C}{P_{B}}
\end{aligned}
$$

Keterangan:

$C F_{t}=$ Cash flow dalam periode pengukuran $t$

$P_{E} \quad=$ Harga saham penutupan pada periode $t$

$P_{B}=$ Harga beli saham atau harga saham pada awal periode $t$

$P C=$ Perubahan harga saham selama periode kepemilikan

Untuk mempermudah pengukuran return saham individual, yang digunakan adalah adjusted closing price atau harga saham yang telah disesuaikan dengan pembagian dividen yang dilakukan oleh perusahaan sehingga pengukuran return saham individual disederhanakan menjadi sebagai berikut :

$$
R_{i t}=\frac{P_{t}-P_{t-1}}{P_{t-1}}
$$

Keterangan:

$R_{i t} \quad=$ Return saham $i$ pada periode ke $t$

$P_{t} \quad=$ Harga saham penutupan periode ini

$P_{t-1}=$ Harga saham penutupan periode sebelumnya

2) Risiko saham SME individual adalah risiko dari masing-masing saham SME individual yang masuk dalam Indeks Pefindo25 (Indonesia), Indeks S\&P BSE SME IPO (India), dan Indeks SME-CHINEXT 100 (China) pada periode pengukuran yaitu tahun 2014 dan periode kepemilikan yaitu 1, 3, dan 6 bulan. Risiko saham SME individual diukur dengan mencari varians dan standar deviasi dari return saham SME individual. Perhitungan dilakukan dengan menggunakan persamaan sebagai berikut (Jones (2014) : 


$$
\begin{aligned}
\sigma^{2} & =\frac{\sum_{i=1}^{n}[X-\bar{X}]^{2}}{n-1} \\
\sigma & =\sqrt{\sigma^{2}}
\end{aligned}
$$

Keterangan:

$\sigma^{2}=$ Variansi dari return saham $i$

$\sigma \quad=$ Standar deviasi saham $\mathrm{i}$

$X \quad=$ Return saham $i$

$\bar{X} \quad=$ Rata-rata return saham $i$

$n \quad$ jumlah return

3) Return portofolio saham SME adalah return dari portofolio saham yang terdiri dari 15 saham SME baik itu di pasar modal Indonesia, India, dan China pada periode pengukuran yaitu tahun 2014 dan periode kepemilikan yaitu 1, 3, dan 6 bulan. Perhitungan return harapan portofolio merupakan rata-rata tertimbang dari return harapan saham individual (Jones, 2014) :

$$
E\left(R_{p}\right)=\sum_{i=1}^{n} w_{i} E\left(R_{i}\right)
$$

6)

Keterangan:

$E\left(R_{p}\right)=$ Return harapan dari portofolio $p$

$w_{i}=$ Bobot saham individual $i$ pada portofolio $p\left(\sum w_{i}=1\right)$

$E\left(R_{i}\right)=$ Return harapan dari saham individual $i$

$n \quad=$ jumlah saham individual dalam portofolio

4) Risiko portofolio saham SME adalah risiko dari portofolio saham yang terdiri dari 15 saham SME baik itu di pasar modal Indonesia, India, dan China pada periode pengukuran yaitu tahun 2014 dan periode kepemilikan yaitu 1, 3, dan 6 bulan. Risiko portofolio dapat dihitung sebagai berikut (Jones, 2014) :

$$
\sigma_{p}^{2}=\sum_{i=1}^{n} w_{i}^{2} \sigma_{i}^{2}+\sum_{i=1}^{n} \quad \sum_{j=1}^{n} w_{i} w_{j} \sigma_{i j}
$$

Keterangan:

$\sigma_{p}^{2} \quad=\quad$ Variansi return dari portofolio $p$

$\sigma_{i}^{2}=$ Variansi return dari saham individual $i$ 
$\sigma_{i j} \quad=\quad$ Kovarian antara return dari saham individual $i$ dan $j$

$w_{i} \quad=$ Bobot saham individual $i$ pada portofolio $p\left(\sum w_{i}=1\right)$

5) Kinerja portofolio saham SME adalah kinerja portofolio saham yang terdiri dari 15 saham SME baik itu di pasar modal Indonesia, India, dan China pada periode pengukuran yaitu tahun 2014 dan periode kepemilikan yaitu 1, 3, dan 6 bulan dan diukur dengan menggunakan Indeks Sharpe. Indeks Sharpe menurut Bodie, et al. (2014) dihitung sebagai berikut :

$$
S=\frac{\bar{r}_{p}-\bar{r}_{f}}{\sigma_{p}}
$$

Keterangan :

$S=$ Sharpe's measure

$\bar{r}_{p}=$ Return rata-rata portofolio

$\bar{r}_{f}=$ Return rata-rata dari aset bebas risiko risiko

$\sigma_{p}=$ Standar deviasi portofolio

Populasi dalam studi komparatif ini adalah seluruh saham SME yang tercatat dan diperdagangkan secara aktif di pasar modal Indonesia (BEI) serta masuk ke dalam Indeks Pefindo25, di pasar modal India (BSE) serta masuk ke dalam Indeks S\&P BSE SME IPO, dan di pasar modal China (SZSE) serta masuk ke dalam Indeks SME-CHINEXT 100 selama periode penelitian yaitu Januari 2014 - Januari 2015. Penentuan jumlah sampel mengacu pada rekomendasi empiris oleh Tandelilin tentang jumlah saham dalam portofolio bahwa untuk meminimalkan risiko portofolio diperlukan sedikitnya 15 saham (Tandelilin, 2010). Kriteria pemilihan sampel adalah memilih 15 saham dengan return tertinggi masing-masing di ketiga pasar modal.

Pengujian hipotesis uji komparatif dengan menggunakan teknik ANOVA satu jalur pada kinerja portofolio saham SME di Pasar Modal Indonesia, India, dan China. Uji ANOVA satu jalur digunakan dalam analisa untuk menguji 
perbedaan rata-rata indeks kinerja portofolio saham SME pada Pasar Modal Indonesia, China dan India. Menurut Hadi (2015), asumsi yang harus dipenuhi dalam ANOVA adalah a) Populasi yang akan diuji berdistribusi normal, b) varian masing-masing populasi satu sama lain tidak menunjukkan perbedaan yang signifikan (homogen), c) sampel diambil secara random, terpisah satu sama lain dari masing-masing populasinya (independen).

Dalam pengujian ANOVA, jika terdapat $\mathrm{n}$ random sampel yang diambil dari setiap populasi sebanyak $\mathrm{k}$ dengan nilai rata-rata $\mu_{1}, \mu_{2}, \mu_{3}, \ldots, \mu_{\mathrm{k}}$ dan varian $=\sigma^{2}$ maka dapat disusun hipotesis (Walpole, 2007):

$$
\begin{gathered}
H_{0}: \mu_{1}=\mu_{2}=\mu_{3}=\cdots=\mu_{k} \\
H_{1}: \text { minimal satu rata }- \text { rata sampel tidak sama }
\end{gathered}
$$

Keterangan:

$\mu_{1}=$ rata-rata kinerja portofolio saham SME di pasar modal Indonesia

$\mu_{2}=$ rata-rata kinerja portofolio saham SME di pasar modal China

$\mu_{3}=$ rata-rata kinerja portofolio saham SME di pasar modal India

Perhitungannya :

$$
\begin{aligned}
& \left.S S T=\sum_{i=1}^{k} \sum_{j=1}^{n}\left(X_{i j}-\bar{X}_{. .}\right)^{2} \ldots \ldots \ldots \ldots \ldots \ldots \ldots \ldots \ldots \ldots \ldots . \ldots . \ldots \ldots\right)
\end{aligned}
$$

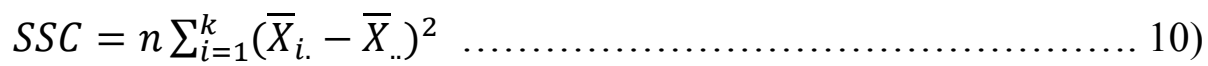

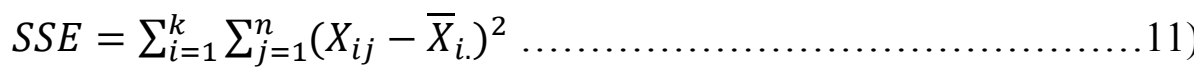

$$
\begin{aligned}
& S S T=S S C+S S E
\end{aligned}
$$

Keterangan :

$\mathrm{SSE}=$ Sum of Square Error

Tabel 1.

Analisis Varian (ANOVA)

\begin{tabular}{ccccc}
\hline VARIASI & SS & df & MSS & F hitung \\
\hline KOLOM & SSC & $k-1$ & \multirow{2}{*}{$M S S C=\frac{S S C}{k-1}$} & $\frac{M S S C}{M S S E}$ \\
\hline
\end{tabular}




\begin{tabular}{lccc}
\hline ERROR & SSE & $k(n-1)$ & MSSE $=\frac{S S E}{k(n-1)}$ \\
TOTAL & SST & $n k-1$ & \\
\hline
\end{tabular}

Keterangan :

SS = Sum of Square

MSS = Mean Sum of Square

df = Degree of Freedom / derajat kebebasan

$\mathrm{F} \quad=\mathrm{F}$ hitung

Kriteria pengujian :

$H_{0}$ ditolak jika $F_{\text {hitung }}>F_{\text {tabel }}$

$H_{0}$ ditolak jika Sig. $<\propto$

Uji ANOVA dilakukan dengan menggunakan bantuan aplikasi IBM SPSS for Statistics 22.

\section{HASIL PENELITIAN DAN PEMBAHASAN}

\section{Return dan Risiko Portofolio Saham SME}

Return portofolio saham SME dengan periode kepemilikan 1, 3 dan 6 bulan di Pasar Modal Indonesia, China dan India adalah sebagaimana Tabel 2.

Tabel 2.

\section{Return dan Risiko Portofolio Saham SME}

\begin{tabular}{lccccccccc}
\hline & \multicolumn{3}{c}{ Indonesia } & \multicolumn{3}{c}{ China } & \multicolumn{3}{c}{ India } \\
& $\mathbf{1}$ bln & $\mathbf{3}$ bln & $\mathbf{6}$ bln & $\mathbf{1}$ bln & $\mathbf{3}$ bln & $\mathbf{6 ~ b l n}$ & $\mathbf{1}$ bln & $\mathbf{3}$ bln & $\mathbf{6}$ bln \\
\hline $\begin{array}{l}\text { Expected } \\
\text { Return }\end{array}$ & $3.27 \%$ & $8.29 \%$ & $17.49 \%$ & $10.16 \%$ & $36.68 \%$ & $84.73 \%$ & $6.55 \%$ & $20.43 \%$ & $36.38 \%$ \\
$\begin{array}{l}\text { Variance } \\
\text { Standar }\end{array}$ & $0.18 \%$ & $0.32 \%$ & $0.18 \%$ & $0.72 \%$ & $1.77 \%$ & $3.81 \%$ & $0.94 \%$ & $4.92 \%$ & $7.78 \%$ \\
$\begin{array}{l}\text { Deviasi } \\
\text { Sumber: Data diolah, } 2016\end{array}$ & & & & & & & & \\
\hline
\end{tabular}

\section{Kinerja Portofolio Saham SME}

1) Kinerja Portofolio Saham SME di Pasar Modal Indonesia 
Return rata-rata aset bebas risiko dihitung dengan menghitung rata-rata BIrate pada periode Januari 2014 - Januari 2015).

Tabel 3. Kinerja Portofolio Saham SME di Pasar Modal Indonesia

\begin{tabular}{ccccc}
\hline Periode & RP & RF & SD & IS \\
\hline 1 bln & $3.27 \%$ & $0.63 \%$ & $4.23 \%$ & 0.62 \\
3 bln & $8.29 \%$ & $1.89 \%$ & $5.68 \%$ & 1.13 \\
6 bln & $17.49 \%$ & $3.78 \%$ & $4.30 \%$ & 3.19 \\
\hline
\end{tabular}

Sumber : Data diolah, 2016

2) Kinerja Portofolio Saham SME di Pasar Modal China

Return rata-rata aset bebas risiko diperoleh dari rata-rata suku bunga bank sentral China (PBC base interest rate) periode Januari 2014 - Januari 2015).

Tabel 4.

Kinerja Portofolio Saham SME di Pasar Modal China

\begin{tabular}{ccccc}
\hline Periode & RP & RF & SD & IS \\
\hline 1 bln & $10.16 \%$ & $0.49 \%$ & $8.46 \%$ & 1.14 \\
3 bln & $36.68 \%$ & $1.48 \%$ & $13.31 \%$ & 2.65 \\
6 bln & $84.73 \%$ & $2.95 \%$ & $19.53 \%$ & 4.19 \\
\hline \multicolumn{2}{r}{ Sumber : Data diolah, 2016 } & & &
\end{tabular}

3) Kinerja Portofolio Saham SME di Pasar Modal India

Return rata-rata aset bebas risiko diperoleh dari rata-rata suku bunga bank sentral India (RBI repo rate) pada periode Januari 2014 - Januari 2015).

Tabel 5. Kinerja Portofolio Saham SME di Pasar Modal India

\begin{tabular}{ccccc}
\hline Periode & RP & RF & SD & IS \\
\hline 1 bln & $6.55 \%$ & $0.67 \%$ & $9.70 \%$ & 0.61 \\
3 bln & $20.43 \%$ & $2.00 \%$ & $22.19 \%$ & 0.83 \\
6 bln & $36.38 \%$ & $3.99 \%$ & $27.90 \%$ & 1.16 \\
\hline \multicolumn{5}{l}{ Sumber : Data diolah, 2016} \\
\end{tabular}

\section{Analisa Varian}

Uji asumsi dipenuhi antara lain : 1) Sampel berasal dari kelompok yang independen dimana sampel diambil dari tiga pasar modal yang berbeda yaitu di 
Pasar Modal Indonesia, China dan India, 2) Uji normalitas dengan Uji Shapiro Wilk diperoleh nilai Sig. untuk kinerja dari portofolio saham SME di pasar modal Indonesia, China dan India adalah masing-masing 0,360, 0,989 dan 0,780 (lebih besar daripada 0,05) sehingga data kinerja portofolio saham SME di pasar modal Indonesia, China dan India berdistribusi normal, 3) Uji homogenitas dengan aplikasi IBM SPSS Statistics 22 diperoleh nilai signifikansi 0,220 (lebih besar dari 0,05) sehingga varian dari kinerja dari portofolio saham SME di pasar modal Indonesia, China dan India adalah sama.

Tabel 6.

Hasil Analisis Varian (ANOVA)

\begin{tabular}{lccrcr}
\hline & $\begin{array}{c}\text { Sum of } \\
\text { Squares }\end{array}$ & df & Mean Square & F & Sig. \\
\hline Between Groups & 4.851 & 2 & 2.426 & 1.711 & .258 \\
Within Groups & 8.508 & 6 & 1.418 & & \\
Total & 13.359 & 8 & & & \\
\hline Sumber : Hasil uji dengan aplikasi IBM SPSS Statistics 22 & & &
\end{tabular}

Berdasarkan Tabel 6, nilai signifikansi $(p$-value $)=0,258$, dengan demikian secara statistik pada taraf nyata/tingkat signifikansi 0,05 maka Ho diterima, sehingga diperoleh bahwa perbedaan rata-rata kinerja pada portofolio saham SME di Pasar Modal Indonesia, China dan India tidak signifikan.

\section{Komparasi Return Portofolio Saham SME}

Return portofolio saham SME yang dibentuk dari 15 saham SME di Pasar Modal Indonesia, China dan India menunjukkan semakin lama jangka waktu kepemilikan portofolio, semakin tinggi return yang diperoleh. Return tertinggi pada penelitian di ketiga pasar modal diperoleh pada periode kepemilikan selama 6 bulan.

Tabel 7. 


\section{Return Portofolio Saham SME}

\begin{tabular}{crrr}
\hline & Indonesia & \multicolumn{1}{c}{ China } & \multicolumn{1}{c}{ India } \\
\hline 1 bulan & $3.27 \%$ & $10.16 \%$ & $6.55 \%$ \\
3 bulan & $8.29 \%$ & $36.68 \%$ & $20.43 \%$ \\
6 bulan & $17.49 \%$ & $84.73 \%$ & $36.38 \%$ \\
\hline \multicolumn{2}{l}{ Sumber $:$ Data diolah, 2016} & &
\end{tabular}

Berdasarkan Tabel 7, return portofolio saham SME di Pasar Modal China jauh melampaui return portofolio saham SME di Indonesia maupun di India. Return tertinggi di Pasar Modal China adalah pada periode kepemilikan 6 bulan dengan return sebesar $84.73 \%$.

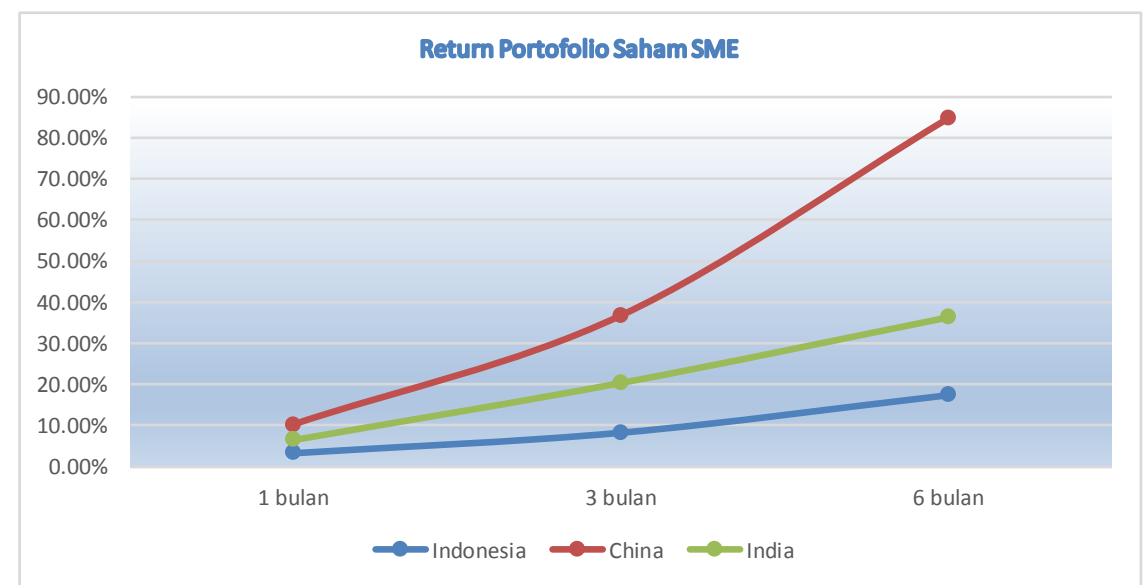

Gambar 2. Return Portofolio Saham SME

Pertumbuhan GDP mengindikasikan pertumbuhan ekonomi suatu negara, pertumbuhan ekonomi yang membaik tentunya akan meningkatkan daya beli masyarakat dan pada akhirnya akan meningkatkan profitabilitas perusahaan (Tandelilin, 2010). Berdasarkan Data Bank Dunia (2016), GDP China pada tahun 2014 adalah sebesar USD 10,351 triliun dengan pertumbuhan sebesar 7,3\%, GDP India adalah sebesar USD 2,042 triliun dengan pertumbuhan sebesar 7,2\%, dan GDP Indonesia adalah sebesar USD 890 miliar dengan pertumbuhan sebesar 5\%. Berdasarkan Grafik 5.1, return portofolio saham SME di China pada periode 
Ni Luh Putu Sri Sandhi, Ida Bagus Panji Sedana, dan Luh Gede Sri Artini. Studi Komparatif....

tahun 2014 menunjukkan nilai yang lebih baik dibandingkan dengan di India dan Indonesia sejalan dengan pertumbuhan ekonomi yang lebih baik dari negara tersebut.

\section{Komparasi Return Bebas Risiko (Risk-free Rate)}

Menurut Tandelilin (2010), tingkat bunga yang tinggi adalah salah satu sinyal negatif terhadap harga saham. Kenaikan tingkat suku bunga akan menyebabkan peningkatan return yang diinginkan atas investasi pada suatu saham. Investor memantau perkembangan kebijakan bank sentral sebagai otoritas moneter khususnya kebijakan terkait tingkat suku bunga (Jones, 2014). Tingkat suku bunga merupakan indikator untuk mengetahui perkembangan ekonomi suatu negara. Tingkat suku bunga atau risk free rate di Indonesia, China dan India pada periode tahun 2014 adalah sebagai berikut :

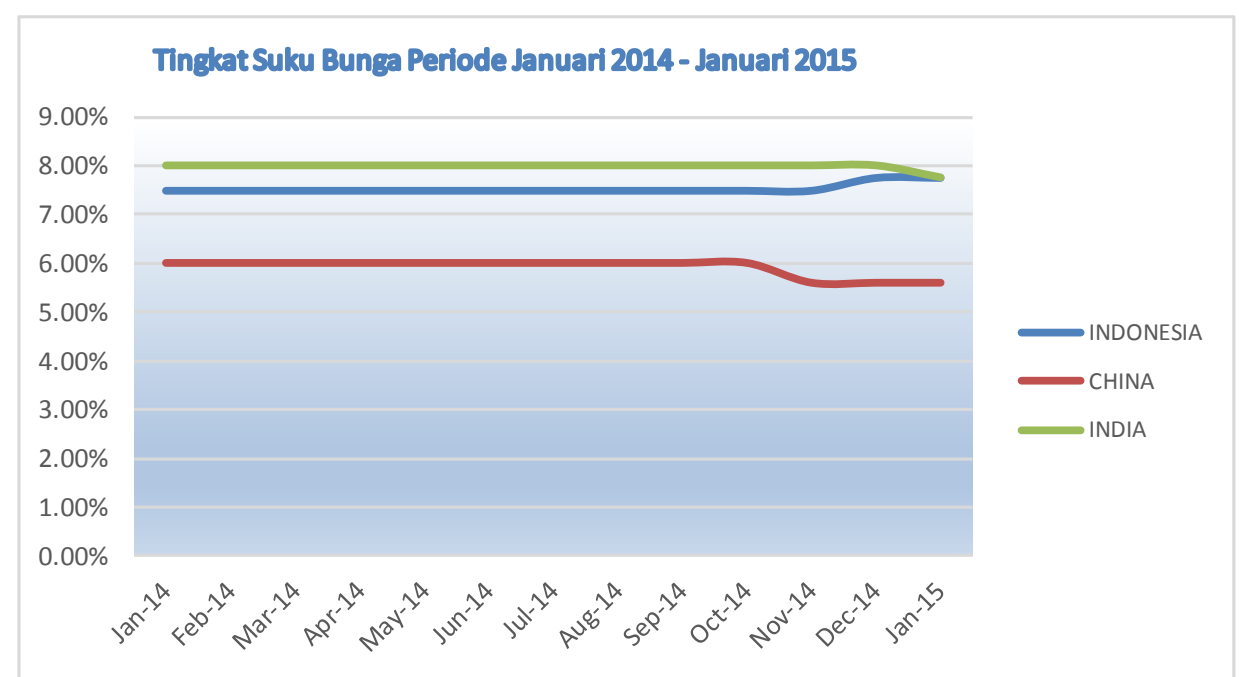

Gambar 3. Tingkat Suku Bunga Periode Januari 2014 - Januari 2015

Berdasarkan Grafik 5.2, return aset bebas risiko (risk-free rate) China pada periode Januari 2014 sampai dengan Januari 2015 yang dikeluarkan oleh The People's Bank of China (PBC) rata-rata adalah sebesar 5,91\% per tahun, lebih 
rendah dibandingkan Indonesia (Bank Indonesia) yaitu rata-rata sebesar 7,55\% per tahun serta India (The Reserve Bank of India) yaitu sebesar rata-rata 7,98\% per tahun. Perbedaan tingkat suku bunga pada periode penelitian diketahui bahwa tingkat suku bunga di China paling rendah jika dibandingkan dengan di Indonesia dan di India yang memiliki tingkat suku bunga tertinggi diantara ketiga negara. Hal tersebut tentunya berpengaruh terhadap pasar modal di masing-masing negara.

\section{Komparasi Risiko Portofolio Saham SME}

Perbedaan dari return aktual yang diterima dengan return harapan disebut sebagai risiko. Semakin besar perbedaannya, maka risiko investasi semakin besar (Tandelilin, 2010). Menurut Jones (2014), besarnya risiko suatu investasi dipengaruhi oleh berbagai sumber seperti : interest rate risk, inflation risk, market risk, financial risk, business risk, liquidity risk, currency risk dan country risk.

Berdasarkan hasil penelitian, risiko portofolio saham SME di Indonesia, China dan India adalah sebagai berikut :

Tabel 8.

Risiko Portofolio Saham SME

\begin{tabular}{crrr}
\hline & Indonesia & \multicolumn{1}{c}{ China } & \multicolumn{1}{c}{ India } \\
\hline 1 bulan & $4.23 \%$ & $8.46 \%$ & $9.70 \%$ \\
3 bulan & $5.68 \%$ & $13.31 \%$ & $22.19 \%$ \\
6 bulan & $4.30 \%$ & $19.53 \%$ & $27.90 \%$ \\
\hline \multicolumn{4}{l}{ Sumber $:$ Data diolah, 2016}
\end{tabular}

Berdasarkan Tabel 8, risiko portofolio saham SME yang terbesar adalah di India pada periode kepemilikan 6 bulan yaitu sebesar 27,90\% diikuti oleh China dan kemudian di Indonesia dengan risiko terkecil. 


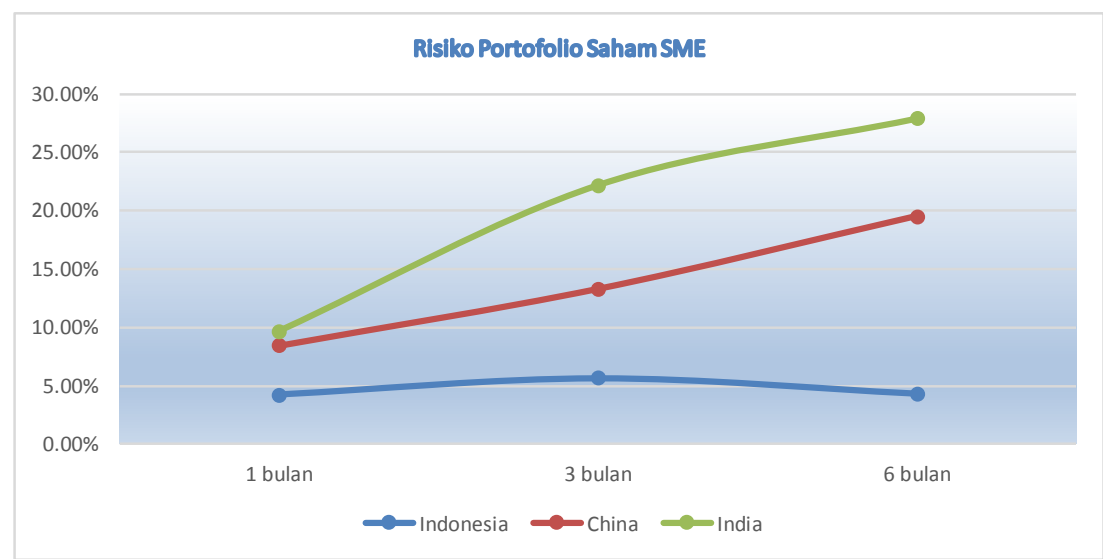

Gambar 4. Risiko Portofolio Saham SME

Perbedaan besar risiko portofolio saham SME di Indonesia, China dan India dapat dipengaruhi oleh berbagai sumber risiko seperti risiko tingkat suku bunga dimana diketahui pada periode penelitian tingkat suku bunga di ketiga negara berbeda dan tingkat suku bunga tertinggi yaitu sebesar 7,98\% per tahun diberlakukan di India. Pertumbuhan ekonomi yang melambat di China menjadi 7,3\% pada tahun 2014 merupakan sumber risiko bisnis dalam investasi di China (World Bank, 2015).

\section{Komparasi Kinerja Portofolio Saham SME (Indeks Sharpe)}

Hasil penelitian terhadap portofolio yang dibentuk dari 15 saham SME (Indeks Pefindo25) dengan return tertinggi pada periode kepemilikan 1, 3 dan 6 bulan menghasilkan kinerja yang lebih baik dibandingkan dengan kinerja IHSG dan kinerja Indeks LQ45 pada periode Januari 2014 - Januari 2015 berdasarkan pengukuran kinerja dengan Indeks Sharpe.

Tabel 9.

Indeks Sharpe di Pasar Modal Indonesia (BEI)

\begin{tabular}{cccc}
\hline Periode & $\begin{array}{c}\text { Portofolio } \\
\text { SME }\end{array}$ & $\begin{array}{c}\text { INDEKS SHARPE } \\
\text { IHSG }\end{array}$ & LQ45 \\
\hline $1 \mathrm{bln}$ & 0.62 & 0.55 & 0.62
\end{tabular}




\begin{tabular}{crrr}
3 bln & 1.13 & 0.73 & 1.05 \\
6 bln & 3.19 & 1.13 & 1.54 \\
\hline \multicolumn{2}{l}{ Sumber : Data diolah, 2016}
\end{tabular}

Hasil kinerja portofolio saham SME di Pasar Modal Indonesia untuk periode kepemilikan 1, 3 dan 6 bulan masing-masing adalah $(0,62),(1,13)$, dan $(3,19)$.

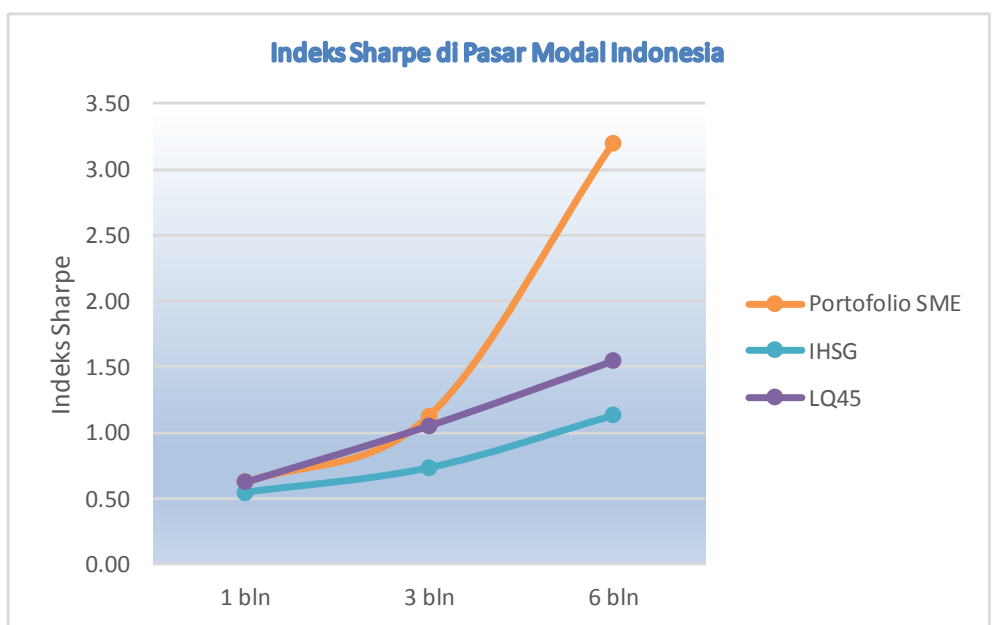

Gambar 5. Kinerja di Pasar Modal Indonesia

Kinerja portofolio saham SME di Pasar Modal China yang dibentuk dari 15 saham SME pada Indeks SME-CHINEXT 100 pada periode Januari 2014 Januari 2015 dengan periode kepemilikan 1, 3, dan 6 bulan jika dibandingkan dengan indeks komposit dan indeks saham A-list di Shenzhen Stock Exchange (Shenzhen Composite Index dan kinerja Shenzhen A-Share Stock Price Index) juga menunjukkan kinerja yang lebih baik.

Tabel 10. Indeks Sharpe di Pasar Modal China (SZSE)

\begin{tabular}{cccc}
\hline Periode & $\begin{array}{c}\text { Portofolio } \\
\text { SME }\end{array}$ & $\begin{array}{c}\text { INDEKS SHARPE } \\
\text { SZSE Comp. } \\
\text { Index }\end{array}$ & $\begin{array}{c}\text { SZSE A-Share } \\
\text { Stock Price Index }\end{array}$ \\
\hline 1 bln & 1.14 & 0.63 & 0.63 \\
3 bln & 2.65 & 1.00 & 1.00 \\
6 bln & 4.19 & 2.17 & 2.16 \\
\hline
\end{tabular}

Sumber : Data diolah, 2016 
Ni Luh Putu Sri Sandhi, Ida Bagus Panji Sedana, dan Luh Gede Sri Artini. Studi Komparatif....

Hasil kinerja portofolio saham SME di Pasar Modal China untuk periode kepemilikan 1, 3 dan 6 bulan masing-masing adalah $(1,14),(2,65)$, dan $(4,19)$.

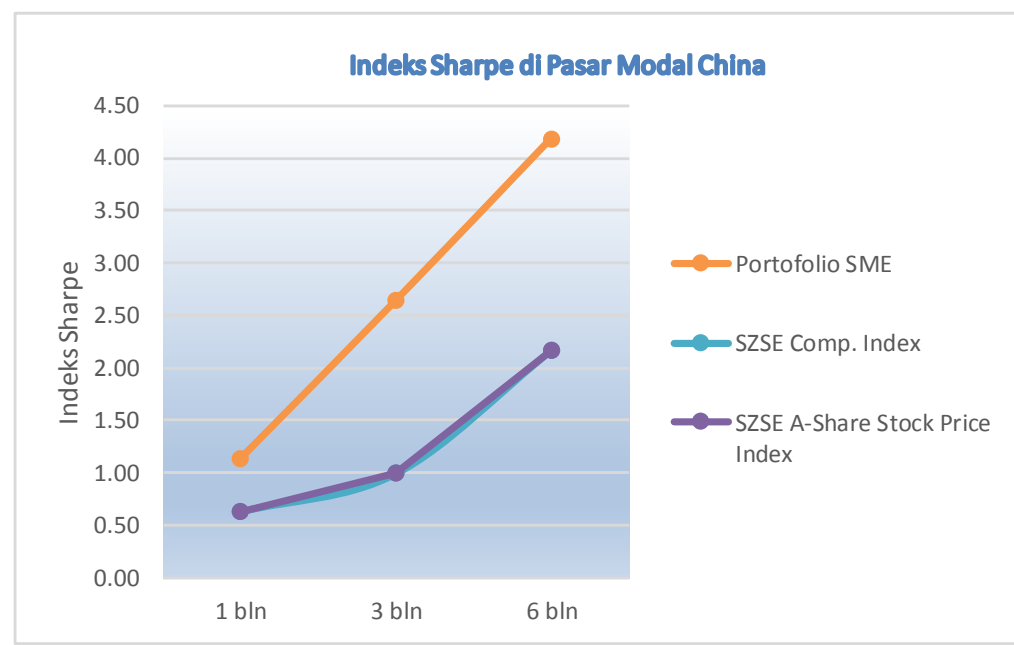

Gambar 6. Kinerja (Indeks Sharpe) di Pasar Modal China

Hasil penelitian di Pasar Modal India terhadap kinerja saham SME yang dibentuk dari 15 saham SME pada Indeks BSE-SME IPO periode Januari 2014 Januari 2015 dengan periode kepemilikan 1,3 dan 6 bulan jika dibandingkan dengan kinerja indeks saham kapitalisasi besar (S\&P BSE 200 Index), menunjukkan kinerja yang lebih baik sedangkan jika dibandingkan dengan kinerja indeks komposit ( $\& \& P$ BSE SENSEX Index), kinerja portofolio saham SME masih lebih rendah.

Tabel 11.

Indeks Sharpe di Pasar Modal India (BSE)

\begin{tabular}{cccc}
\hline Periode & $\begin{array}{c}\text { Portofolio } \\
\text { SME }\end{array}$ & $\begin{array}{c}\text { INDEKS SHARPE } \\
\text { S\&P BSE } \\
\text { SENSEX }\end{array}$ & $\begin{array}{c}\text { S\&P BSE 200 } \\
\text { Index }\end{array}$ \\
\hline 1 bln & 0.61 & 0.75 & 0.23 \\
3 bln & 0.83 & 1.73 & 0.09 \\
6 bln & 1.16 & 2.39 & 0.27 \\
\hline
\end{tabular}

Sumber : Data diolah, 2016 
Hasil kinerja portofolio saham SME di Pasar Modal China untuk periode kepemilikan 1, 3 dan 6 bulan masing-masing adalah $(0,61),(0,83)$, dan $(1,16)$.

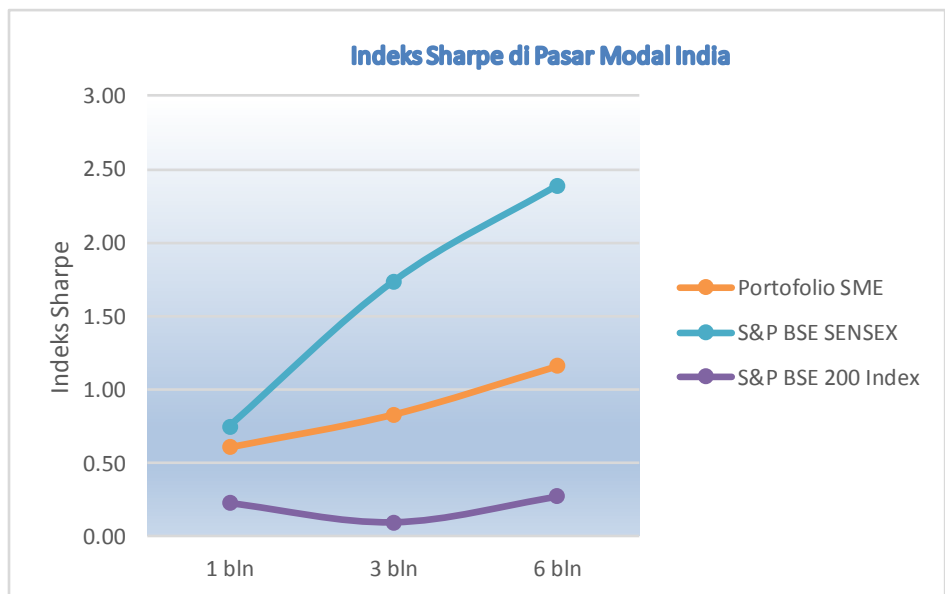

Gambar 7. Kinerja (Indeks Sharpe) di Pasar Modal India

Hasil studi yang dilakukan mendukung penelitian Tudor, et al (2014) yang menemukan bahwa pada pasar modal Romania (Bucharest Stock Exchange) berinvestasi pada saham-saham SME akan mendapatkan kinerja pasar terbaik berdasarkan hasil perhitungan dengan risk-adjusted performance.

Komparasi kinerja portofolio saham SME berdasarkan Indeks Sharpe di Pasar Modal Indonesia, China dan India menunjukkan hasil kinerja portofolio saham SME yang berbeda dimana di Pasar Modal China menunjukkan kinerja yang terbaik baik itu pada periode kepemilikan 1, 3 dan 6 bulan. Kinerja dari portofolio saham SME di Pasar Modal Indonesia menunjukkan kinerja yang lebih baik daripada kinerja portofolio saham SME di Pasar Modal India untuk periode kepemilikan 1,3 dan 6 bulan.

Tabel 12.

Komparasi Kinerja Portofolio Saham SME

\begin{tabular}{cccc}
\hline & Indonesia & China & India \\
\hline 1 bulan & 0.62 & 1.14 & 0.61
\end{tabular}




\begin{tabular}{cccc}
3 bulan & 1.13 & 2.65 & 0.83 \\
6 bulan & 3.19 & 4.19 & 1.16 \\
\hline \multicolumn{3}{l}{ Sumber $:$ Data diolah, 2016}
\end{tabular}

Berdasarkan Tabel 12, kinerja portofolio saham SME terbaik diperoleh pada periode kepemilikan 6 bulan baik itu di Pasar Modal Indonesia, China dan India. Investasi saham merupakan investasi jangka panjang dan investor akan memperoleh return positif yang lebih besar dari investasi pada periode waktu yang lebih lama karena perusahaan tersebut akan mencapai keunggulan kompetitif yang berkelanjutan (Damodaran, 2007).

Kinerja portofolio saham SME di Pasar Modal China lebih baik dibandingkan di Indonesia dan India antara lain disebabkan oleh perolehan return portofolio saham SME yang lebih tinggi yaitu masing-masing sebesar 10,16\%, $36,68 \%$ dan $84,73 \%$ untuk periode kepemilikan 1, 3 dan 6 bulan, tingkat suku bunga bebas risiko yang paling rendah dengan rata-rata sebesar 5,91\% per tahun. Kinerja portofolio saham SME di Pasar Modal China terbaik dibandingkan di Indonesia dan India walaupun risiko portofolionya saham SME relatif tinggi namun masih lebih rendah daripada risiko portofolio saham SME di India.

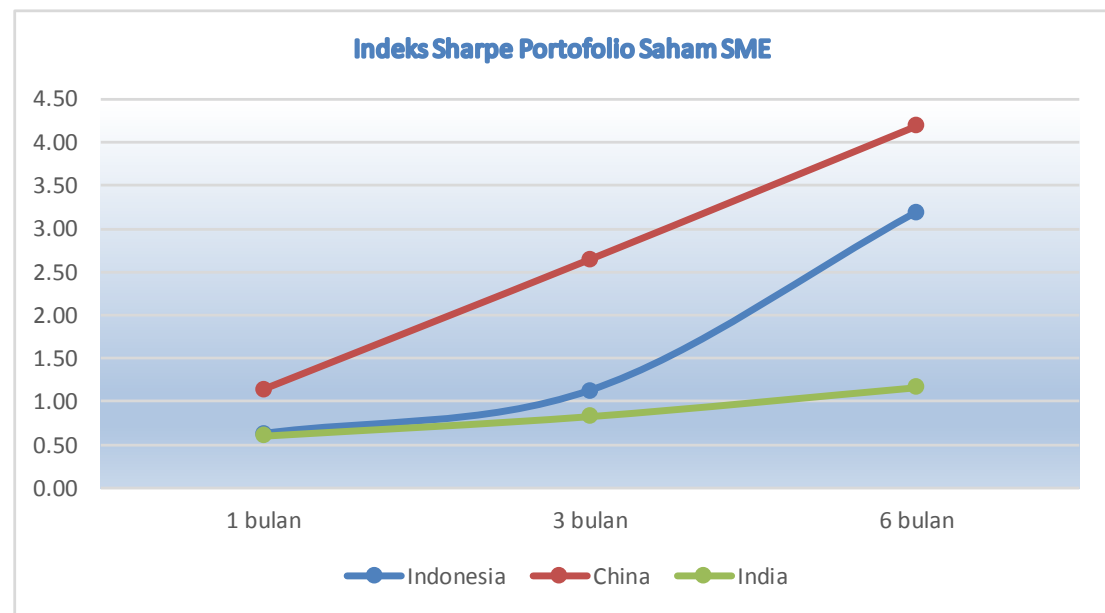

Gambar 8. Komparasi Kinerja (Indeks Sharpe) 
Kinerja portofolio saham SME di India paling rendah walaupun perolehan return portofolio yang relatif tinggi namun disertai dengan risiko portofolio yang tinggi bahkan paling tinggi jika dibandingkan dengan di Indonesia dan China. Kinerja portofolio saham SME di India yang rendah juga diakibatkan tingkat suku bunga bebas risiko di India tertinggi dibandingkan dengan di Indonesia dan China yaitu sebesar rata-rata 7,98\% per tahun selama periode penelitian.

Kinerja portofolio saham SME di Indonesia menunjukkan nilai yang cukup baik walaupun lebih rendah daripada di China namun lebih tinggi jika dikomparasi dengan kinerja portofolio saham SME di India. Kinerja portofolio saham SME di Indonesia yang cukup baik diakibatkan oleh perolehan return yang relatif cukup tinggi dan risiko portofolio saham SME yang terendah jika dibandingkan dengan di China dan India. Risiko portofolio saham SME di Indonesia bahkan menurun pada periode kepemilikan 6 bulan yaitu sebesar 4,30\% dari periode kepemilikan selama 3 bulan yaitu sebesar 5,68\%. Tingkat suku bunga bebas risiko di Indonesia masih lebih rendah daripada di India yaitu sebesar ratarata $7,55 \%$ per tahun.

Secara statistik, analisis komparatif terhadap rata-rata kinerja portofolio SME yang telah dibentuk dari saham SME di Pasar Modal Indonesia, China dan India pada periode pengamatan Januari 2014 - Januari 2015 berdasarkan metode analisis varian satu arah diperoleh nilai $\mathrm{F}$ hitung sebesar 1,711 < F tabel sebesar 5,14 atau nilai signifikansi ( $p$-value) sebesar 0,258 > 0,05 sehingga pada taraf signifikansi $0,05 \quad \mathrm{H}_{0}$ diterima yang artinya tidak terdapat perbedaan yang signifikan antara rata-rata kinerja portofolio SME di ketiga pasar modal tersebut. 
Ni Luh Putu Sri Sandhi, Ida Bagus Panji Sedana, dan Luh Gede Sri Artini. Studi Komparatif....

Hasil analisa komparatif secara statistik yang menunjukkan tidak terdapatnya perbedaan yang signifikan pada rata-rata kinerja portofolio saham SME di Pasar Modal Indonesia, China dan India pada periode pengamatan Januari 2014 - Januari 2015 dapat dijelaskan karena keterbatasan periode dalam pembentukan portofolio hanya 1 tahun.

\section{SIMPULAN DAN SARAN}

Dari hasil penelitian dan pembahasan dapat ditarik simpulan, pertama, kinerja portofolio saham SME di Pasar Modal Indonesia menunjukkan kinerja yang lebih baik daripada kinerja IHSG dan Indeks LQ45. Kedua, kinerja portofolio saham SME di Pasar Modal China (SZSE) menunjukkan kinerja yang lebih baik daripada kinerja Shenzhen Composite Index dan kinerja Shenzhen AShare Stock Price Index. Ketiga, kinerja portofolio saham SME di Pasar Modal India (BSE) menunjukkan kinerja yang lebih baik daripada kinerja $S \& P$ BSE 200 Index namun dibandingkan dengan kinerja indeks komposit ( $\& \& P$ BSE SENSEX Index), masih lebih rendah. Keempat, hasil komparasi kinerja dari portofolio saham SME di Pasar Modal Indonesia, China dan India diperoleh kinerja terbaik pada kinerja portofolio saham SME di Pasar Modal China dan yang terendah adalah pada kinerja portofolio saham SME di Pasar Modal India. Kelima, secara statistik berdasarkan uji komparasi dengan ANOVA satu arah diperoleh perbedaan rata-rata kinerja portofolio saham SME di Pasar Modal Indonesia, China dan India tidak signifikan pada taraf signifikansi 0,05.

Beberapa saran yang dapat diberikan antara lain, pertama, investor dapat mempertimbangkan untuk memilih saham-saham SME dalam portofolio investasi 
yang terbukti menghasilkan kinerja yang lebih baik dibandingkan dengan kinerja indeks komposit dan kinerja indeks saham A-list. Kedua, otoritas di pasar keuangan Indonesia dapat mempertimbangkan pembentukan bursa khusus SME sebagai kebijakan untuk dapat membantu perkembangan SME di Indonesia khususnya dari sisi pembiayaan. Ketiga, pada penelitian selanjutnya, analisis kinerja portofolio SME dapat dilengkapi dengan analisis kinerja Indeks Treynor dan Jensen untuk pengukuran kinerja apabila portofolio saham sudah terdiversifikasi dengan baik serta dapat dikembangkan dengan pembentukan portofolio saham SME yang terdiversifikasi secara internasional. Keempat, penelitian selanjutnya dapat dilengkapi dengan analisa terhadap faktor fundamental keuangan SME baik itu leverage, profitabilitas, penilaian pasar terhadap cash flow perusahaan, penjualan perusahaan, nilai buku perusahaan dan ukuran perusahaan sebagai faktor untuk menentukan kinerja portofolio saham SME.

\section{IMPLIKASI PENELITIAN}

Implikasi hasil penelitian dimana portofolio saham SME menghasilkan kinerja yang relatif lebih baik jika dibandingkan dengan kinerja indeks saham $A$ list dan kinerja indeks komposit di ketiga Pasar Modal baik itu di Indonesia, China dan India dapat menjadi bahan pertimbangan bagi investor untuk berinvestasi dalam saham-saham SME. Bagi investor internasional, berinvestasi pada saham SME di Indonesia dapat menjadi pertimbangan dimana hasil penelitian yang menunjukkan kinerja portofolio saham SME di Indonesia lebih unggul dari kinerja portofolio saham SME di India. 
Kinerja dari portofolio saham SME di Indonesia yang relatif baik dapat menjadi pertimbangan bagi otoritas di pasar keuangan di Indonesia untuk mengembangkan bursa khusus bagi SME sehingga dapat mendukung perkembangan SME lebih lanjut di Indonesia dan menjadi pemecahan masalah sumber pembiayaan yang kurang bagi SME.

\section{REFERENSI}

Asian Development Bank. 2014. Asia SME Finance Monitor 2013

Asian Development Bank. 2015. Asia SME Finance Monitor 2014

Bailey, J. 1992. Evaluating Benchmark Quality. Financial Analysts Journal, MayJune. pp. $33-39$.

Barth, J. Lin, D. Yost, K. 2011. Small and Medium Enterprise Financing in Transition Economies. International Atlantic Economic Society, No.39, pp.19-38

Chandra, Liliana, Hapsari, Y. 2013. Analisis Pembentukan Portofo Optimal dengan Menggunakan Model Markowitz untuk Saham LQ 45 Periode 20082012. Jurnal Manajemen, Vol 1 No. 1 Mei 2013, pp.41-65

Damodaran, A. 2007. Return on Capital (ROC), Return on Invested Capital (ROIC) and Return on Equity (ROE) : Measurement and Implications. Stern School of Business

Elton, E. dan Gruber, M. 1997. Modern Portfolio Theory, 1950 to Date. Journal of Banking and Finance, No 21, pp. 1743 -1759.

Graham, B. Dodd, D. 2009. Security Analysis. Sixth Edition, McGraw -Hill, New York

Hadi, S. 2015. Statistik, Pustaka Pelajar

Harwood, A. Konidaris, T. 2015. SME Exchanges in Emerging Market Economies A Stocktaking of Development Practices. Policy Research Working Paper 7160, World Bank Group

Husnan, S. 2009. Dasar-dasar Teori Portofolio dan Analisis Sekuritas. Yogyakarta, UPP STIM YKPN 
India Times. 2013. BSE becomes the SME hub in India: 86\% companies trading above issue price. www.articles.economicstime.indiatimes.com

International Monetary Fund. 2016. World Economic Outlook : Subdued Demand :Symptoms and Remedies. Washington. October

Indrayanti. Yuli N. Darmayanti, N. 2013. Penentuan Portofolio Optimal dengan Model Markowitz pada Saham Perbankan di Bursa Efek Indonesia. EJurnal Manajemen Universitas Udayana, Vol. 2, No. 8

Jensen, M. 1968. The Performance of Mutual Funds in the Period 1945 -1964. The Journal of Finance, Vol 23.

Jogiyanto, H. 2014. Teori portofolio dan Analisis Investasi. Edisi Kesembilan, Yoyakarta, BPFE.

Jones, C. 2014. Investment: Principles and Concepts $12^{\text {th }}$ Edition. John Willey \& Sons, New York.

Kazan. Halim. Uludag, K. 2014. Credit Portfolio Selection According to Sectors in Risky Environments: Markowitz Practice. Asian Economic and Financial Review, 4(9), pp.1208-1219

Keown, M. Scott, P. 2005. Manajemen Keuangan Prinsip-Prinsip dan Aplikasi. Jakarta, Pearson Education Inc.

Lorie, J. Dodd, P. Kimton, M. 1985. The Stock Market Theories and Evidence. Richard D Irwin Inc., Homewood, Illinois 60430.

Manulang, M. 2012. Optimalisasi Kinerja Portofolio Investasi di Indonesia. Tesis, Universitas Indonesia

Markowitz, H. 1952. Portfolio Selection. Journal of Finance, 7, pp.77-91.

Mishra, B. 2013. Financing of Micro, Small and Medium Enterprise: Challenges and Strategies. Asia Pacific Journal of Management \& Entrepreneurship Research (APJMER), Volume 2, Issue 2, April 2013

Moskowitz, T. Grinblatt, M. 1999. "Do Industries Explain Momentum”. Journal of Finance, 54

Naveen, C. 2014. Application of Sharpe Single Index Model to BSE. Management Today, Vol.4 (April-June), No.2 
Paskawati, L. 2012. Kinerja Portofolio Saham Infrastruktur, Keuangan dan Konsumsi Berdasarkan Strategi Investasi Sektoral di Pasar Modal Indonesia. Tesis, Program Pascasarjana Universitas Udayana

PEFINDO. 2013. Kinerja Indeks Pefindo25 Tahun 2012: Konsisten Mencatat Pertumbuhan Yang Terbaik. www.pefindo.com

Roll, R. 1981. A Possible Explanation of The Small Firm Effect. The Journal of Finance, Vol.XXXVI, No.4

Sekaran, U. Bougie, R. 2013. Research Methods for Business : a skill building approach. 6th ed, Wiley, Chichester.

Sharpe, G. Jeffery V. 1995. Investment. Prentice Hall, Inc., New Jersey.

Shinozaki, S. 2014. Capital Market Financing for SMEs: A Growing Need in Emerging Asia. ADB Working Paper Series on Regional Economic Integration

Singh, R. Suresh. Deshmukh, G. 2009. The competitiveness of SMEs in a globalized economy. Management Research Review, Vol. 33 Iss 1 pp. 54 65

SZSE. 2013. Stock Market Performance Report of Shenzhen Stock Exchange in 2013. www.szse.com

Tambunan, T. 2013. Ongoing trade facilitation improvement: Its impact on export-oriented small and medium-sized enterprises in Indonesia. AsiaPacific Research and Training Network on Trade, No.133, Oktober 2013

Tandelilin, E. 2010. Portofolio dan Investasi : Teori dan Aplikasi. Yogyakarta, Kanisius

Tudor, C. Tudor, M. Anghel, A. 2014. Performance of SMEs stocks portfolios at Bucharest Stock Exchange. Procedia - Social and Behavioral Sciences, Vol.150, pp.772 - 777

Van Eck Global. 2015. Independent companies driving China's growth. Market Vectors

Walpole, R. Myers, R. Myers, S. Ye, K. 2007. Probability \& Statistics for Engineers \& Scientists. Eight Edition, Pearson Prentice Hall

Wood, D. Pratt, C. Hoff, B. 2010. Investing in the Backbone of Emerging Markets. Working Paper from Boston College Center for Corporate Citizenship's Institute for Responsible Investment, www.bccc.net. 